\title{
Reportable Event
}

National Cancer Institute

\section{Source}

National Cancer Institute. Reportable Event. NCI Thesaurus. Code C54034.

An event that must be reported to a regulatory or governing agency. 